\title{
Evaluation Method on Destruction and Removal Efficiency of Perfluorocompounds from Semiconductor and Display Manufacturing
}

\author{
Jee-Yon Lee, Jin Bok Lee, Dong Min Moon, Jun Hyung Souk, ${ }^{\dagger}$ Seung Yeon Lee, and Jin Seog Kim \\ Division of Hetrologv for Quality Life, Korea Research Institute of Standards and Science, Yuseong, Daejeon 305-600, Korea \\ ${ }^{*}$ E-mail. jkimakiss.re.kr \\ †Samsthy Electronics Co, LTD, Giheung, Iongin +49-711, Korea \\ ${ }^{\ddagger}$ Samsung Adwanced Institute of Technolog, Gihetung, Yongin 4+9-721, Korea \\ Received February 2, 2007
}

\begin{abstract}
Recently, the semiconductor and display industries have tried to reduce the emissions of perfluorocompounds (PFCs) from the globally environmental regulation. Total amount of $\mathrm{PFC}$ emission can be calculated from the flow rate and the partial pressures of PFCs. For the precise measurement of PFC emission amount. the mass flow controlled helium gas was continuously injected into the equipment of which scrubber efficiency is being measured. The partial pressures of PFCs and helium were accurately measured using a mass spectrometer in each sample extracted from inlet and outlet of the scrubber system. The flow rates are calculated from the partial pressures of helium and also. PFC destniction and removal efficiency (DRE) of the scrubber is calculated from the partial pressure of PFC and the flow rate. Under this method. the relative expanded uncertainties of the flow rate and the partial pressures of PFCs are $\pm 2 \%(k=2)$ in case the concentrations of $\mathrm{NF}_{3}$ and $\mathrm{SF}_{6}$ are as low as $100 \mu \mathrm{mol} / \mathrm{mol}$
\end{abstract}

Key Words : PFC. Destruction and removal efficiency (DRE), Scrubber efficiency. Global warning. Gas mass spectrometer.

\section{Introduction}

The Kyoto Protocol has officially come into effect on Feb. 16. 2005 as Russia finally ratified the treaty. The protocol demands a $5.2 \%$ cut down the emission of the greenhouse gases including $\mathrm{CO}_{2}$ from the industrialized world by 2012 . The six most prominent greenhouse gases are carbon dioxide $\left(\mathrm{CO}_{2}\right)$, methane $\left(\mathrm{CH}_{4}\right)$, nitrous oxide $\left(\mathrm{N}_{2} \mathrm{O}\right)$. hydrofluorocarbons (HFCs) perfluorocarbons and sulfur hexafluoride $\left(\mathrm{SF}_{6}\right)$. Perfluorocompounds ( $\mathrm{PFCs}$ ) are commonly used in semiconductor and display manufacturing for plasma etching chemical vapor deposition (CVD), and chamber cleaning. ${ }^{1.2}$ These PFCs such as $\mathrm{CF}_{4}$ and $\mathrm{C}_{2} \mathrm{~F}_{6}$ are mostly chemically inert that intensely absorb infrared radiation with relatively long lifetimes $(50,000$ and 10,000 years. respectively) into the atmosphere. giving high global warming potential (GWP) (with the GWP $\mathrm{P}_{100}$ of 6500 and 9200. respectively $)^{3}$ compared to $\mathrm{CO}_{2}{ }^{4.5}$ Although $\mathrm{NF}_{3}$ does not currently have a GWP recognized by the Intergovernmental Panel on Climate Change (IPCC). the $\mathrm{NF}_{3}$ emissions are also considered as one of the regulated compounds. Molina et al. have estimated a GWP 100 of 8000 and an atmospheric lifetime of 740 years for $\mathrm{NF}_{3}$ compound ${ }^{6}$ Recently. the environmental health and safety (EHS) goals for semiconductor industry have been focused to reduce perfluorocompound emission because of their high global warming potentials and long atmospheric lifetimes. Also. many studies have been experimentally accomplished on abatement of perfluorocompounds by various techniques including plasma technologies. ${ }^{7.11}$ However. there is no special guideline to estimate the amount of PFC emissions produced during semiconductor manufacturing processes.

There are four alternative methods (Tier 1. Tier 2a. Tier 2b. Tier 2c) for estimating FC (fluorinated compound) emissions available using the basic methodological principles outlined in the IPCC. Guidelines for other source categories. The use of the 'Tier' terminology' corresponds to increasing data requirements and sophistication of the enission estimation process. The choice of methods depends on data availability and is outlined in the 'Decision Tree' for FC enissions from semiconductor manufacturing (see IPCC. 2000). The World Semiconductor Council (WSC) members. including the US. Europe. Japan. Korea and Taiwan. unanimously adopted the Tier $2 \mathfrak{c}$ method to estimate annual PFC emissions and to monitor the progress of emission reduction. 12 The Tier $2 c$ method uses companyspecific parameters. but does not distinguish between etching and cleaning. The Tier $2 \mathrm{c}$ method was also utilized in this work. According to the Tier $2 \mathfrak{c}$ method the amount of $\mathrm{PFC}$ emissions can be calculated as follows:

Emissions of $\mathrm{FC}_{\mathrm{r}}=(\mathrm{l}-\mathrm{h}) \times\left[\mathrm{FC}_{7} \times\left(\mathrm{l}-\mathrm{C}_{1}\right) \times\left(\mathrm{l}-\mathrm{a}_{2} \times \mathrm{d}_{1}\right)\right](\mathrm{l})$ Where:

$\mathrm{FC}_{i}=$ purchases amount of a gas $i$ in $\mathrm{kg}\left(\mathrm{CF}_{4}, \mathrm{C}_{2} \mathrm{~F}_{6} \mathrm{C}_{3} \mathrm{~F}_{8}\right.$. $\mathrm{C}_{4} \mathrm{~F}_{8}, \mathrm{NF}_{3}, \mathrm{SF}_{6}$ )

$h=$ fraction of $\mathrm{PFC}$ remaining in shipping container (heel) after use

$\mathrm{C}_{i}=$ use rate (fraction destroỵed or transformed) for each gas $i$

$a_{i}=$ fraction of gas volume fed into in processes with emission control technologies (company- or plantspecific) 
$\mathrm{d}_{i}=$ fraction of gas $i$ destroyed by the emission control technology

In the above equation, the emission amount of PFC gas is a function of scrubber efticiency. The scrubber efficiency is determined by the amount of the specific component emission rather than by the mole fraction of PFCs at inlet and outlet of scrubber. There are two ways to determine the scrubber efficiency. One is measuring the concentrations and the mass flow rates both at inlet and outlet. The other is measuring the concentration of the analyte when the emission control equipment is on and off. In general, the scrubber efficiency is obtained by on-line based on Fourier Jransform Infrared Spectroscopy (Fl]R $)^{13.1 .4}$ or real time Quadrupole Mass Spectrometry (QMS) method. ${ }^{15.16}$ Under these methods, the $\mathrm{PFC}$ amount has to be calculated considering the flow rate, pressure, and temperature at inlet and outlet of the scrubber. ${ }^{13.17}$ Here, we suggest a reliable method to obtain the efficiencies of various scrubbers in accordance with the guidelines by the IPCC. The scrubbers of which efficiency are measured in this work were actually installed in display manufacturing lines to eliminate the $\mathrm{PFC}$ exhausted from the plasma etching and the CVD cleaning processes.

\section{Experiment}

Accurate flow rate measurement is critical in this method. The flow rate can be measured with a calibrated flow meter at inlet and outlet of the scrubber. Or, as we introduce in this paper, one can add a stable chemical species in the process line and estimate a flow rate by measuring partial pressure of that species. The chemical species must have no interference with the analytes and be indestructible inside the scrubber. Helium was added as a stable species with calibrated flow rate, and the concentration of helium was measured. In our method, the measurements are taken off-site to determine the DRE (Destruction and Removal Efficiency) of the emission reduction technology. Helium gas was added into the inlet of scrubber system at a constant rate. Samples were collected into the stainless steel cylinder at both inlet and outlet of the scrubber. The partial pressures of PFCs and helium gas in each sample cylinder were measured using a mass spectrometer. The DRE can be calculated ignoring the effects generated from the pressure as well as the temperature because these factors remain constant during the measurements.

The performance test of the measurement system must be performed for the verification and the uncertainty evaluation for this method. The reference gas mixtures were used for this purpose. The quality of used reference gas mixtures has been already evaluated through key comparison between National Metrology Institutes (NMIs) under the supervision by CCQM (Consultative Committee of Amount of Substance) in BIPM (International Bureau of Weights and Measures). ${ }^{18}$

Gas Sampling To remove the PFCs discharged from semiconductor manufacturing process, a scrubber is usually installed at the end of process line. A schematic diagram of the sampling set-up for the scrubber evaluation is shown in Figure 1. The mass flow controller (MFC. BROOK Model 5850 E, USA) calibrated against a calibrated wet meter (SINAGAWA SEIKI Corp, Japan) was used to adınit pure He gas with the constant rate of I LPM into the front port of the scrubber inlet. For the sampling cylinder preparation, the I L stainless steel cylinders were evacuated by a rotary pumping system to $2.67 \mathrm{P} \mathrm{P}$ at the temperature of $60^{\circ} \mathrm{C}$ for 3 hours to remove all remaining gases including water from the cylinder. The samples were taken from the process line into the cylinders through the needle valve and the $0.2 \mathrm{~mm}$ hole sized orifice which was utilized for homogenous collection for four minutes.

In this sampling system, the destruction removal

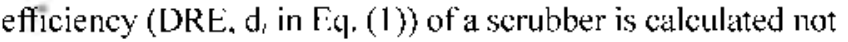
based on the volumetric concentration of inlet (in) and outlet (out) gas, but based on mass flow rates as shown below:

$$
\mathrm{DRE}-1-\mathrm{M}_{i m / l} / \mathrm{M}_{i n}
$$

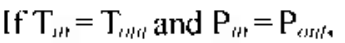

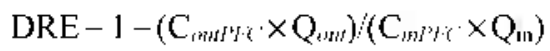

Where:

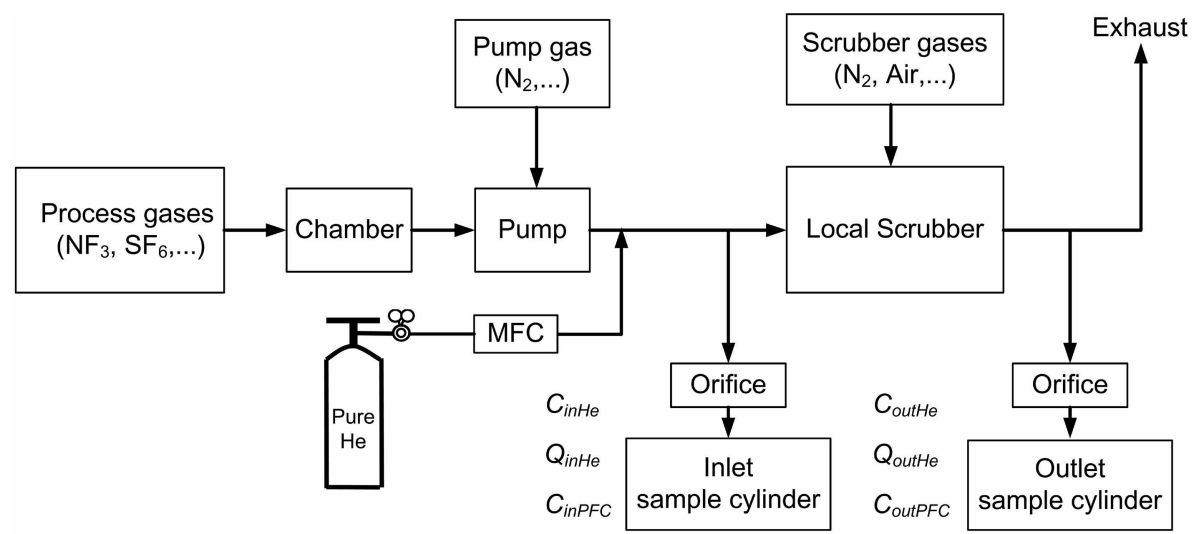

Figure I. Schematic diagram of the sampling sy stem. "I he samples were taken from the process line into the cylinders through the needle valve and the $0.2 \mathrm{~mm}$ hole sized orilice. 
$\mathrm{M}_{j+1}=\mathrm{P} \Gamma \mathrm{C}$ 's mass flow rate entering the scrubber

$\mathrm{M}_{\text {ruf }}=$ PFC's mass flow rate leaving the scrubber

$\mathrm{T}_{i t}=$ gas temperature entering the scrubber

$\mathrm{T}_{t+m i}=$ gas temperature leaving the scrubber

$P_{\mathrm{j}, t}=$ gas pressure entering the scrubber

$P_{r m i}=$ gas pressure leaving the scrubber

$\mathrm{C}_{\text {in } m}=\mathrm{P \Gamma C}$ 's volumetric concentration entering the scrubber

$\mathrm{C}_{\mathrm{tm} t / \%}=\mathrm{PFC}$ 's volumetric concentration leaving the scrubber

$\mathrm{Q}_{m}=$ gas volumetric flow rate entering the scrubber

$\mathrm{Q}_{\text {on }}=$ gas volumetric flow rate leaving the scrubber

Since the He gas was added to flow into the sampling system with a constant rate. the amount of each species was calculated from multiplying the partial pressures of analyte by the flow rate obtained from le concentration in both inlet and outlet. When the analyles are measured by a gas mass spectrometer (Finigan MAT 271) for the samples taken from a process, the effect due to the temperature can be ignored once the temperature of samples is under the equilibrium in the cylinder before the measurements. Accordingly, the DRE can be simplified to the Eq. (3). This means that the DRE value can be determined by the gas concentration ratio

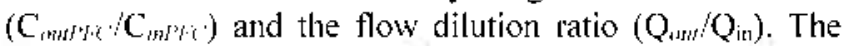
$Q_{n}$ and $Q_{\text {est }}$ are calculated from a known flow rate of pure IIc gas according to the Eq. (4).

$$
\mathrm{Q}_{m}=1 / \mathrm{C}_{m+1 / k}, \mathrm{Q}_{\text {mm }}=1 / \mathrm{C}_{\text {mothli }}
$$

Where, $\mathrm{C}_{m}$ He and $\mathrm{C}_{\text {enthe }}$ are the He gas volumetric concentration at inlet and outlet of a scrubber, respectively.

Analytical Instrument and Verification The magnetic sector type precision gas mass spectrometer (Finnigan MAT $271 / 45$, Germany) was used to measure the concentrations of the analytes and the He gas. The principle of a gas mass spectrometer (Gas-MS) is as follows. The gas sample is expanded into the sampling chamber at the constant temperature of $60^{\circ} \mathrm{C}$. The sample gas in the chamber flows into the mass spectrometer through the pin-hole type injection port which allows molecular flow. The Figure 2 illustrates the inlet of the measurement system which was a) ready demonstrated in earlier work. ${ }^{10}$ All of $1 / 2^{\prime \prime}$ or $1 / 4^{11}$ stainless steel tubing was connected by welding or VCR fitting to maintain the high-vacuum condition in the inlet system. The sample cylinder was attached with 1/4" stainless steel fitting. The turbo molecular pump (PFEJFFER vacuum. ']SU261) was utilized to maintain the high vacuum (below $1.33 \times 10^{1} \mathrm{~Pa}$ ) with minimizing contamination of hydrocarbons, and the pressure of a sample gas was checked by the two baratron gauges (1000 mbar and I mbar maximum reading pressure. MKS type 270 ).

In the mass spectrometer, the gas molecules are ionized with $50 \mu \mathrm{A}$ emission current and analyzed with a specific $\mathrm{m} / \mathrm{z}$. value as they travel through magnetic sector with $8 \mathrm{kV}$ acceleration voltage. Two detectors, Faraday cup and secondary electron multiplier (SEM), are installed. The mass resolutions are variable from 250 to 2500 , which is enough to separate $\mathrm{CO}$ and $\mathrm{N}_{2}$ at $\mathrm{m} / z=28$. The Gas-MS, unlike FIIR and QMS, has a wide dynamic range $\left(1 \times 10^{6}\right)$ and therefore, allows one-point calibration for a quantitative analysis. The selection of $\mathrm{m} / \mathrm{z}$ for a specific chemical species in mass spectrometer is chosen the largest characteristic peaks. If any interference occurred in selected peak, it can be corrected based on the peak ratios obtained from known gas mixture (standard reference gas mixtures).

The standard gas mixtures were prepared with the relative expanded uncertainty of $\pm 0.1 \%(k=2)$ using a gravimetric tmethod in accordance with the ISO guide $6142 .{ }^{20}$ The real applications of these standards were well demonstrated in earlier work. ${ }^{21.22}$ The sensitivity of each gas can be determined by using standard gas mixtures. The sensitivity of a specific component gas is calculated from the injected gas concentration, the pressure in the mass spectrometer, and the output signal (in volt) as shown in Eq. (5). An unknown sample concentration is calculated by Eq. (6).

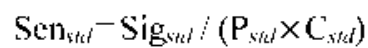

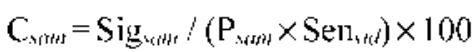

Where,

$S_{\text {Sen }}=$ sensitivity for a selected peak (V/mbar)

Sigw $w=$ signal value for a standard (V)

Sigrrm = signal value for a sample (V)

$\mathrm{P}_{\mathrm{s} w}=$ injection pressure for a standard (mbar)

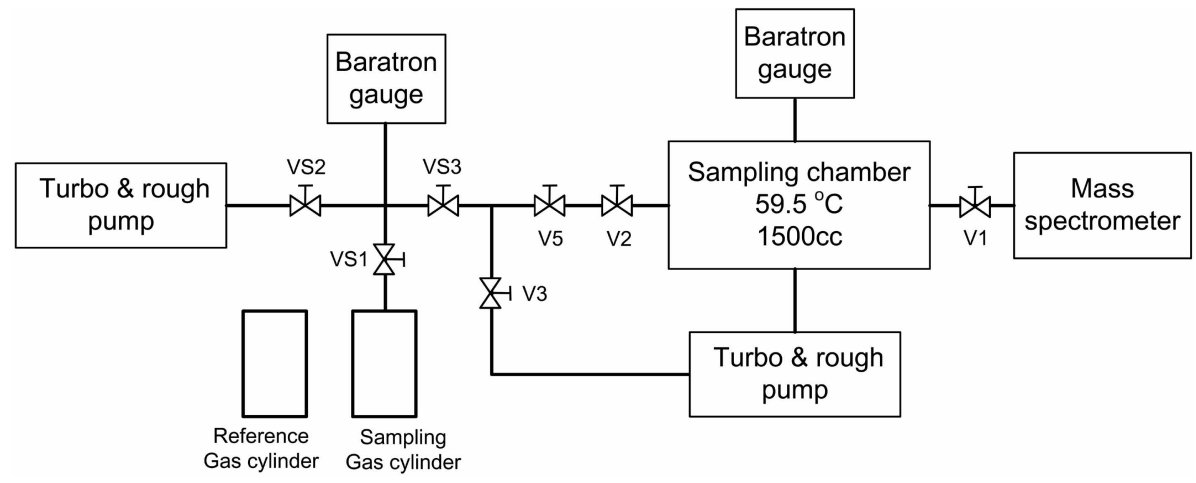

Figure 2. Schematic diagram of sample injection system in at gas-mass spectrometer. The stainless stect tubing was connected by welding or VCR fitting to maintain the high-vacuum condition in the inlet system. The sample gas in the chamber flows into the mass spectrometer through the pin-hole type injection port which allows molecular flows. 
$\mathrm{P}_{\text {sam }}=$ injection pressure for a sample (mbar)

$\mathrm{C}_{\text {sid }}=$ concentration of a component gas in a standard gas mixture (\% $\%$ mol $/ \mathrm{mol})$

$\mathrm{C}_{\text {sam }}=$ concentration of a component gas in a sample $(\% \mathrm{~mol} / \mathrm{mol})$

Because of wide range of linearity. sensitivity value. once obtained can be used to measure a wide range of the analyte concentration. $\% \mathrm{~mol} / \mathrm{mol}$ to $\mu \mathrm{mol} / \mathrm{mol}$ level. Also this application was checked by using several standard gas mixtures with different concentrations including $\mu \mathrm{mol} / \mathrm{mol}$ level of $\mathrm{NF}_{3}$ and $\mathrm{SF}_{6}$.

To verify the DRE measurement method. we examined the lower limit of detection. linearity and repeatability of the precision gas mass spectrometer (Finnigan MAT 271) using the primary standard gas mixtures including $\mathrm{He}$. $\mathrm{SF}_{6}$, and $N F_{3}$. The detection limits of the analytical system were obtained from a $\mathrm{S} / \mathrm{N}$ ratio $(\mathrm{S} / \mathrm{N}=2)$ to be $0.3 \mu \mathrm{mol} / \mathrm{mol}$ and $0.4 \mu \mathrm{mol} / \mathrm{mol}$ for $\mathrm{SF}_{6}$ and $\mathrm{NF}_{3}$. respectively when the pressure was $0.5 \mathrm{mbar}$ in the sample chamber of the mass spectrometer. The linearity of detection system was tested measuring the several standard gas mixtures with different concentrations. For example, when the sample pressures were regulated from 0.024 to $0.525 \mathrm{mbar}$. the sensitivities (signal to injection chamber pressure ratio. in $\mathrm{V} / \mathrm{mbar}$ ) were constant within a relative uncertainty of $\pm 0.1 \%(k=1)$. As a verification of this analytical method. the known gas mixhures was applied with lower concentration as samples to evaluate those concentrations by other standard gas mixtures with much higher concentration as reference gases (Table 1). All measurements were performed using a Faraday detector. The repeatability ( 3 consecutive measurements) was $\pm 0.6 \%$ for $100 \mu \mathrm{mol} / \mathrm{mol}$ level of $\mathrm{SF}_{6 .} \pm 0.8 \%$ for $100 \mu \mathrm{mol} / \mathrm{mol}$ level of $\mathrm{NF}_{3}$ and $\pm 0.1 \%$ for $1 \% \mathrm{~mol} / \mathrm{mol}$ level of He as a relative standard deviation. Table 1 shows the difference between the prepared and measured concentrations of each component. The residuals in Table 1 are all less than $1 \%$ of gravinetric concentrations. This means that our method can apply to PFC analysis from $\mu \mathrm{mol} / \mathrm{mol}$ level to $\% \mathrm{~mol} / \mathrm{mol}$ level. The measurements of PFC and He concentrations are the major source of the uncertainty for the scrubber efficiency. The maximum relative expanded uncertainty is $\pm 2 \%(k=2)$ in measuring $100 \mu \mathrm{mol} / \mathrm{mol} \mathrm{level} \mathrm{of} \mathrm{PFC.} \mathrm{In}$ this level. therefore, the DRE value can be determined within $\pm 2 \%$ relative expanded uncertainty.

Table 1. Results of verification test in the precision gas mass spectrometer

\begin{tabular}{ccccc}
\hline \multirow{2}{*}{ Compound } & \multicolumn{4}{c}{ Concentration $(\mathrm{mol} / \mathrm{mol})$} \\
\cline { 2 - 5 } & $\begin{array}{c}\text { Gravimetric } \\
\text { (A) }\end{array}$ & $\begin{array}{c}\text { Measured } \\
(\mathrm{B})^{\sigma}\end{array}$ & $\begin{array}{c}\text { Residual } \\
\text { (A-B) }\end{array}$ & $\begin{array}{c}\text { Reference } \\
\text { gas }\end{array}$ \\
\hline $\mathrm{SF}_{5}$ & $99.90 \times 10^{-6}$ & $100.64 \times 10^{-6}$ & $0.74 \times 10^{-6}$ & $0.999 \times 10^{-2}$ \\
$\mathrm{NF}_{3}$ & $103.42 \times 10^{-6}$ & $103.73 \times 10^{-6}$ & $0.31 \times 10^{-6}$ & $1.022 \times 10^{-2}$ \\
$\mathrm{He}$ & $10.285 \times 10^{-2}$ & $10.244 \times 10^{-2}$ & $-0.041 \times 10^{-2}$ & Pure He \\
& $1.194 \times 10^{-2}$ & $1.193 \times 10^{-2}$ & $-0.001 \times 10^{-2}$ & \\
\hline
\end{tabular}

"These results were estimated by using sensiticity values obtained with reference gases.
Table 2. Analytical results of sample gases for application to real sample

\begin{tabular}{|c|c|c|c|c|}
\hline \multirow[t]{2}{*}{ Compound } & \multicolumn{2}{|c|}{$\begin{array}{c}\text { Gas concentration } \\
(\% \mathrm{~mol} / \mathrm{mol})\end{array}$} & \multicolumn{2}{|c|}{$\begin{array}{c}\text { Gas flow rate }(\mathrm{L} / \mathrm{min}) \\
\text { at } 22^{\circ} \mathrm{C}\end{array}$} \\
\hline & $\mathrm{C}_{i n}$ & $\mathrm{C}_{\text {out }}$ & $Q_{\text {in }}{ }^{\prime \prime}$ & $Q_{\text {out }}{ }^{a}$ \\
\hline $\mathrm{H}_{2}$ & 0.6002 & 0.0018 & 62.1 & 376.8 \\
\hline$N_{2}$ & 97.491 & 81.546 & & \\
\hline $\mathrm{O}_{2}$ & 0.017 & 17.33 & & \\
\hline $\mathrm{Ar}$ & 0.001 & 0.778 & & \\
\hline $\mathrm{CO}_{2}$ & 0.001 & 0.074 & & \\
\hline $\mathrm{He}$ & 1.6106 & 0.2654 & & \\
\hline $\mathrm{NF}_{3}$ & 0.8793 & 0.0050 & & \\
\hline Total & 100.00 & 100.00 & & \\
\hline
\end{tabular}

The flow rates were calculated from He concentration by Eq. (4).

Applications. We applied this method to determine the destruction and removal efficiency (DRE) of a PFC scrubber. ${ }^{23}$ The scrubber type is an electrically heated device which has been used to remove $\mathrm{NF}_{3}$ in the $\mathrm{CVD}$ etching process. The scrubber was tested in its manufacturer's laboratory. For the application of our method. samples were collected as described earlier in Figure 1. The operation condition of process chamber was identical to when it was operated in the CVD etching process. We set the flow rate of the nitrogen to $-60 \mathrm{~L} / \mathrm{min}$ and of the pure $\mathrm{NF}_{3}$ to $-500 \mathrm{~mL}$ min with the ball flow meter, and pure $\mathrm{He}$ to $1000 \mathrm{~mL} / \mathrm{min}$ with the MFC (BROOK. model $5850 \mathrm{E}$ ). The flow rates were calibrated at $22^{\circ} \mathrm{C}$ prior to measurement using the wet meter (SINAGAWA SEIKI Corp. Japan. calibrated at Korea Research Institute of Standards and Science). The measurement results of gas composition by mass spectrometer are shown in Table 2. The gas flow rates.s $\mathrm{Q}_{\text {in }}$ and $\mathrm{Q}_{\mathrm{out}}$, are calculated by the Eq. (4) using the concentrations of $\mathrm{He}$ at inlet $\left(\mathrm{C}_{2 m}\right)$ and outlet $\left(\mathrm{C}_{\text {out }}\right)$ of cylinder.

$$
\begin{aligned}
\mathrm{Q}_{i n} & =1 / \mathrm{C}_{\text {in }} \times 100=62.1 \mathrm{~L} / \mathrm{min} . \\
\mathrm{Q}_{\text {out }} & =1 / \mathrm{C}_{\text {outhe }} \times 100=376.8 \mathrm{~L} / \mathrm{min}
\end{aligned}
$$

The DRE is then calculated by the Eq. (3) with the amount of $\mathrm{NF}_{2}$ from inlet and outlet concentrations:

$$
\mathrm{DRE}=1-(376.8 \times 0.0050) /(62.1 \times 0.8793)=0.966
$$

As described in the section 2.1. this method can eliminate uncertainties caused by a fluctuation of the temperature and the pressure during sampling process. Therefore. the uncertainty could be generated from only the partial pressure measurements by the gas mass spectrometer. The DRE of the scrubber applied in this work was found to be $96.6 \%$ $\pm 1.9 \%(k=2)$.

\section{Results and Discussion}

We suggest a method which can measure both efficiencies of the destruction technology and the process chamber in accordance with the Tier 2c. Verification test of the method was carried out using several standard gas mixtures. The DRE of the electrically heated type scrubber applied in this 
work was calculated to be $96.6 \% \pm 1.9 \%(k=2)$. This expanded uncertainty includes uncertainties from the flow rate measurements and from the Gas-MS measurement of $\mathrm{NF}_{3}$ concentration. Thus. we can conclude that this proposed method can be used to evaluate the destruction efficiency of any scrubber with relative expanded uncertainty maximum $\pm 2 \%(k=2)$ up to PFC concentration as low as $0.5 \mu \mathrm{mol} /$ mol.

It is necessary to measure the flow rates going into and out of the destruction technology as IPCC reconumends using the amount of total emission for the PFC removal efficiency evaluation. The amount of a "gas" depends on its partial pressure. volume. and the temperature. Therefore. as IPCC requires. the total flow rate should be normalized to the standard condition $\left(0^{\circ} \mathrm{C}, 1 \mathrm{~atm}\right)$ before it is multiplied with each concentration of the greenhouse gases. The enission amount of each gas can be expressed with these calculated values. There are various ways to determine the gas flow rate generated during the manufacturing processes in the seniconductor or display industries. Our new method employs a noble gas as an internal standard. By measuring the partial pressures of helium and analytes, the relative flow rates of the analytes in the sample can be estimated as compared to the known flow rate of helium. Another way of determining the PFC deconposition efficiency is to measure the concentrations of the analytes when the destruction technology (scrubber or main reaction chamber) is on and when it is off. The ratio of the concentrations would indicate the efficiency. This on and off method. however, is very time-consuning since most of the electrical heater type scrubbers require many hours until they are cooled down. Moreover, turning off the scrubbers in the middle of the manufacturing process is not practical. In our method. helium is the best to use for an internal standard primarily because it is not used in the manufacturing process of semiconductor or display. If the helium is used in the process, one can simply collect the additional sample when the helium flow as an internal standard is off. The difference of helium amount in two samples will give a correct flow rate. The argon could not be used since it exists in the air. which is supplied to the scrubber as an auxiliary gas. Other noble gas like neon and xenon can be used but they are expensive. Any chemical species detectable in a Gas-MS could be the analytes in this method. However. the interferences between the different species in the mixture sample should be corrected.

Note that it is assumed that only analytes and $\mathrm{He}$ gas (internal standard) are present in the collected samples. We ignore all other gas species such as $\mathrm{N}_{2} . \mathrm{O}_{2} . \mathrm{Ar}, \mathrm{HF}$, and $\mathrm{F}_{2}$ which come from the air and the manufacturing processes. This assumption does not significantly affect the calculation of the flow rate according to the following Eq. (9)-(15).

$$
\begin{gathered}
\mathrm{Q}_{t o t}=\mathrm{Q}_{I}+\mathrm{Q}_{2}+\ldots+\mathrm{Q}_{3}+\ldots+\mathrm{Q}_{H e} \\
\mathrm{P}_{\mathrm{I}}=\mathrm{Q}_{i} / \mathrm{Q}_{t o t}
\end{gathered}
$$

where. $Q_{j}$ is a real flow rate of the component $i$ in the gas mixtures. $\mathrm{Q}_{H \varepsilon}$ is a flow rate of helium $(1.000 \mathrm{~L} / \mathrm{min})$, and $\mathrm{P}_{j}$ is a partial pressure of component $i$. If you do not account of Q2 in calculation,

$$
\begin{gathered}
\mathrm{Q}_{t o{ }^{\prime}}=\mathrm{Q}_{t o r}-\mathrm{Q}_{2}=\mathrm{Q}_{1}+\mathrm{Q}_{2}+\ldots+\mathrm{Q}_{i}+\ldots+\mathrm{Q}_{H e} \\
\mathrm{P}_{i}^{\prime}=\mathrm{Q}_{i} / \mathrm{Q}_{\text {rot }}=\mathrm{Q}_{i} /\left(\mathrm{Q}_{\text {Iot }}-\mathrm{Q}_{2}\right)
\end{gathered}
$$

where, Q Q ot is an estimated total flow rate excluding the component gas 2. $\mathrm{P}_{i}^{\prime}$ is an estimated partial pressure of the component $i$ excluding the component gas 2 .

$$
\begin{gathered}
\mathrm{P}_{H_{i}}{ }^{\prime}=\mathrm{Q}_{H e} /\left(\mathrm{Q}_{\text {tor }}-\mathrm{Q}_{2}\right) \\
\left(\mathrm{Q}_{j o t}-\mathrm{Q}_{2}\right)=1.000 \mathrm{~L} / \mathrm{min} / \mathrm{P}_{H e}{ }^{\prime} \\
\mathrm{Q}_{i}=\mathrm{P}_{i}^{\prime} \times\left(\mathrm{Q}_{J o r}-\mathrm{Q}_{2}\right)=\mathrm{P}_{i}^{\prime} / \mathrm{P}_{H e}{ }^{\prime}
\end{gathered}
$$

Therefore. the $Q_{2}$ value does not depend on any other gas component. It only depends on its own calculated partial pressure $\left(\mathrm{P}_{i}{ }^{\prime}\right)$ and the calculated He partial pressure $\left(\mathrm{P}_{\mathrm{He}}{ }^{\prime}\right)$. Being independent of other species in the sample, the calculation of the flow rates for noble gas and analytes would not be affected by any variations of their environment as long as their partial pressures remain constant. Some nonexperts measure the concentration of an analyte directly and identify it with the scrubber efficiency. However. the auxiliary gases continuously flow into the scrubber and this naturally dilutes the analyte concentration. Therefore, the flow rate must be considered for the correction of efficiency calculation.

The advantage of our method is that it allows us to repeat measurements and we can calculate an average of concentrations by collecting a sample for several minutes. This averaging effect compensates for instantaneous fluctuations. On the other hand. the online FTIR measurement method shows several problems: The baseline drifts when the concentration gets lower: Spectral interferences caused by water and the processing gases are difficult to remove: Sampling cell becomes contaminated as the number of measurements increases. which causes the different IR transmittance to the IR cell; The temperature during the measurements should be compensated: flow rate should be measured by other methods. Also, the online QMS method has difficulties in correction of the temperature and pressure effect during sampling from the manufacturing process line. Moreover. this method can not estimate the gas flow rate inside a process line without adding additional known amount of a stable chemical species to the sampling system.

\section{Conclusions}

We suggest a method for the accurate measurements of the scrubber efficiency which provides an averaged value for several minutes during the normal operation. A gas mass spectrometer was used for the measurements and the evacuated stainless steel cỵlinders were used as sampling containers. Helium gas was added into the scrubber system with a constant rate using a calibrated MFC. The concentration of helium was used to calculate correct the flow rate of each analyte used in the manufacturing processes. This method eliminates the effects caused by temperature. pressure. and interferences occurring with the QMS and FTIR 
measurement methods. Moreover. we can estimate PFC consumption rate in a process chamber $\left(\mathrm{C}_{2}\right)$ as well as the destruction and removal efficiency of scrubber $\left(d_{i}\right)$ simultaneously because the exact flow rate of PFC can be obtained from the He concentrations.

Acknowledgements. This work was supported br Electronic Display Industrial Research Association of Korea through the project 'The study on PFC emission from LCD industries`.

\section{References}

1. Van Brunt, R. I.: Herron. J. T. IEEE Trans. Electr. Insul. 1990. 25. 75

2. Tsai. W. T: Chen, H. P.: Hsien, W. Y. Jommal of Loss Prevention in the Process Indtustries 2002. 15.65.

3. Houghton. J. T.: Meira Filho. L. G.: Callander. B. A.: Harris. N.: Kattenberg. A.: Maskell. K. Clinate Change 1995: The Sience of Climate Change, Cambridge University Press: New York. 1996.

4. Vartanian. V.: Goolsbv: B.: Chatterjee, R.: Kachunarik. R.: Babbitt. D.: Reif. R: Tonnis. E. I.: Graves. D. IEEE Tran. Semicon. Manifac. 2004. 17, 483

5. Chang. M. B.: Chang. J. S. Ind Eng. Chem. Res. 2006. 15.4101.

6. Molina. L. T.: Wooldridge. P. J.: Molina. M. J. Geophns. Res. Lett. $1995,22,1873$

7. Radoiu, M. T. Radiation Physics and Chemishy 2004. 69, 113.

8. Stoffels, W. W. Stoffels. E.: Tachibana. K. Jommal of Tacmm Science \& Technologt \& 1998.16.87.
9. Johnson. A. D.: Ridgeway. R. G: Maroulis. P. J. $I E E E$ Trm Senticon. Mamufac. 2004. 17. 491.

10. Mohindra. V.: Chae. H.: Sawin. H. H.: Mocella. M. T. IEEE Tram Semicon. Manufac. 1997. 10. 399

11. Chan. E. M.: Loh, G: Allgood. C. C. IEEE Trom. Senicon 1amufac. 2004, 17,497.

12. IPCC Guidelme. Good practice guidance and uncertainty management in national greenhouse gas inventories. Intergovernmental Panel on Climate Change: 2000: Chapter 3.6. p 243

13. Li. S. N.: Hsu, J. N.; Shih, H. Y.: Lin, S. J.; Hong, J. L. Solid State Teclmologv $2002,45.157$.

14. Guber. A. E.: Kohler, U. J. 1 Kol Struct 1995, 348. 209.

15. Fujii. T.: Arulmozhiraja. S.: Nakamura. M.: Shickawa. Y. Anof Chent. 2001. 73.2937.

16. Stoffels. E.: Stoffels. W. W: Tachibana. K. Rev Sci. Instrim 1998. 69,116

17. Li. S. N.: Hsu. J. N.: Leo. G. H. Seniconductor Fabtech, $14^{\text {th }}$ ed; 2005: 03 .

18. Kiml. J. S.: Moon. D. M.: Kato. K.: Leonid. A.: Konopeltio. L: Kustikow. Y. A.: Guenther. F. R. Hetrologia 2006. 13.080019.

19. Lee. T. Y: Yoo. H. S.: Park. J. S.: Hwang. K. J.: Kim. J. S. J. Chem. Edu. 2005, 82. 288.

20. International Organization for Standardization. ISO 6142: Gas analusis - Preparation of Calibration Gas Mixtwes-Grawimetric Methods. $2^{\text {nd }}$ ed: 2001 .

21. Lee. J. Y: Yoo. H. S.: Marti. K.: Moon. D. M.: Lee. I. B.: Kinn. J S. J. Geophss. Res 2006. H1. D05302

22. Park, S. Y; Kim. J. S.; Lee. J. B.: Esler, M. B.: Davis, R. S. Wielgosz. R. I. Aftrologia $2004,41,387$.

23. Moon. D. M.: Lee J. B.: Lee, J. Y.: Kim. D. H.: Lee. S. H.: Lee. M. G: Kim. J. S. Ahal. Sci. Tech. 2006. 19. 535 